\title{
Espécies de Parmotrema (Parmeliaceae, Ascomycetes liquenizados) com medula pigmentada do litoral centro-sul do Estado de São Paulo
}

\author{
Michel Navarro Benatti ${ }^{1,2}$ e Marcelo Pinto Marcelli ${ }^{1}$
}

Recebido: 05.01.2009; aceito: 17.09.2009

\begin{abstract}
Species of Parmotrema (Parmeliaceae, lichenized Ascomycetes) with pigmented medulla in the centersouth coast of São Paulo State). In a survey of the species pertaining to genera of large parmeliae occurring in the coastal areas of the center-south coastal areas of São Paulo State, Brazil, seven species of Parmotrema A. Massal. with pigmented medulla (P. aurantiacoparvum, $P$. cf. cryptoxanthoides, $P$. endosulphureum, $P$. sorediosulphuratum, $P$. subochraceum and P. sulphuratum) are reported. Identification key, descriptions, commentaries, and illustrations based on collected material are provided for these species.

Key words: mangrove, Parmotrema, pigmented medulla, restinga

RESUMO - (Espécies de Parmotrema (Parmeliaceae, Ascomycetes liquenizados) com medula pigmentada do litoral centrosul do Estado de São Paulo). O levantamento das espécies pertencentes aos gêneros de grandes parmélias do litoral centro-sul do Estado de São Paulo revelou a ocorrência de sete espécies de Parmotrema A. Massal. com medula parcial a totalmente pigmentada ( $P$. aurantiacoparvum, $P$. cf. cryptoxanthoides, $P$. endosulphureum, $P$. sorediosulphuratum, $P$. subochraceum e $P$. sulphuratum). São apresentados chave de identificação, descrições detalhadas, comentários e ilustrações baseados em material brasileiro.

Palavras-chave: manguezal, Parmotrema, medula pigmentada, restinga
\end{abstract}

\section{Introdução}

O gênero Parmotrema A. Massal. é caracterizado pelos lobos de ápices largos e arredondados (com mais de $0,5 \mathrm{~cm}$, muitas vezes ultrapassando 2 ou 3 $\mathrm{cm}$ de largura), ausência de pseudocifelas, ocorrência freqüente de cílios marginais, ampla zona marginal do córtex inferior nua, rizinas geralmente simples, e ascósporos elipsóides de paredes espessas (Brodo et al. 2001, Nash \& Elix 2002). Mais de trezentas espécies são conhecidas em todo o mundo (Nash \& Elix 2002), das quais aproximadamente um terço é citado para o Brasil (Marcelli 2005).

Todas as espécies apresentadas neste trabalho possuem como característica mais evidente a pigmentação parcial ou total da medula, que abrange cores como amarelo claro, amarelo enxofre claro ou escuro, alaranjado forte, ocre ou salmão.

A área abrangida por esta pesquisa e seus respectivos dados geográficos, climáticos e de substratos encontrados na região são descritos em Benatti \& Marcelli (2008). Ela está localizada no litoral centro-sul do Estado de São Paulo, entre as municipalidades de Bertioga e Cananéia.

Sãofornecidos uma chave artificial de identificação, descrições comentadas, dados das localidades e de ambientes para as espécies encontradas.

\section{Material e métodos}

Foram analisadas amostras de coletas recentes e dos últimos 30 anos em todos os municípios da Baixada Santista localizados no litoral centro-sul do Estado de São Paulo, situados abaixo do trópico de Capricórnio e compreendidos entre as municipalidades de Bertioga (4608'03" W, 2351'17' S) e Cananéia (47"55'33” W, 2500'53”'S).

A metodologia utilizada encontra-se descrita em Benatti \& Marcelli (2008). O material foi coletado e identificado conforme Fink (1905), Galloway (1985) e Hale (1979). Foram realizadas excursões pontuais de coleta a várias localidades urbanas e naturais de todos os municípios da região, tendo sido obtidas amostras de todos os ecossistemas costeiros que compõem

1. Instituto de Botânica, Caixa Postal 3005, 01061-970 São Paulo, SP, Brasil

2. Autor para correspondência: michel_benatti@yahoo.com.br 
a localidade de estudo, que foram acrescentadas às amostras obtidas nas últimas décadas.

A metodologia de análises químicas utilizadas seguiu Asahina \& Shibata (1954), Walker \& James (1980), White \& James (1985), Huneck \& Yoshimura (1996), Bungartz (2001) e Orange et al. (2001), com pequenas mudanças ou adaptações. Foram feitas análises por testes de coloração e por cromatografia em camada delgada (CCD) em solvente $\mathrm{C}$.

Embora sejam discutidos os aspectos mais relevantes pertinentes a cada uma das espécies encontradas, outras comparações e detalhes podem ser encontrados em Benatti (2005).

\section{Resultados}

No litoral centro-sul do Estado de São Paulo foram encontradas sete espécies de Parmotrema com medula pigmentada, duas parcialmente e cinco totalmente pigmentada. Quase não há trabalhos brasileiros publicados que descrevem espécies desse grupo, exceto por Eliasaro \& Donha (2003), que mencionam e descrevem P.flavomedullosum Hale e P.permutatum (Stirton) Hale, embora que para o Estado de São Paulo e para alguns outros estados haja trabalhos estrangeiros de M. E. Hale contendo descrições e que citam espécimes de P.endosulphureum (Hillman) Hale, P. sulphuratum (Nees \& Flotow) Hale (Hale
1965) e de P. subochraceum Hale (Hale 1990). Ainda sobre trabalhos brasileiros, Marcelli (1990) apenas citou P. permutatum e P. sulphuratum para o Estado de São Paulo. Um único trabalho estrangeiro publicado menciona $P$. cryptoxanthoides (Kurokawa) Hale ex DePriest \& B. Hale, e apenas para o Estado do Paraná (Kurokawa 1974).

As espécies tratadas neste artigo foram comumente mencionadas e/ou descritas para o Estado de São Paulo em trabalhos não efetivamente publicados, sendo que dados como descrições, comentários e chaves de identificação constam somente de teses e dissertações (Fleig 1997, Ribeiro 1998, Eliasaro 2001, Benatti 2005, Canêz 2005, Donha 2005, Spielmann 2005, Jungbluth 2006).

Das espécies encontradas, P. permutatum, P. sorediosulphuratum Eliasaro \& Donha e P. subochraceum apresentam propagação por sorédios enquanto que $P$. aurantiacoparvum Sipman, $P$. endosulphureum e $P$. sulphuratum apresentam propagação por isídios, e somente $P$. cf. cryptoxanthoides não forma propágulos vegetativos.

Foram encontrados ascósporos somente nos apotécios de espécimes de $P$. subochraceum, enquanto que conídios estavam presentes em espécimes de $P$. endosulphureum e P. permutatum.

Chave para as espécies de Parmotrema com medula pigmentada do litoral centro-sul do Estado de São Paulo

1. Talo com medula parcialmente pigmentada (ambas as espécies sorediadas)

2. Talo membranáceo, medula com pigmento alaranjado K+ vermelho escuro, disposto em hifas entrelaçadas com outras não pigmentadas na porção inferior, às vezes formando manchas; $\mathrm{K}-, \mathrm{C}-, \mathrm{KC}+$ róseo, $\mathrm{P}+$ alaranjado (ácido protocetrárico) P. subochraceum

2. Talo subcoriáceo, medula branca na porção superior com várias colorações diferentes na metade inferior, amarela, salmão e ocre; $\mathrm{K}-$ na porção superior e $\mathrm{K}+$ amarelado, $\mathrm{C}+$ róseo->alaranjado na inferior (eumitrinas e ácido girofórico ) . P. permutatum

1. Talo com medula totalmente pigmentada (espécies com sorédios, isídios ou sem propágulos)

3. Medula totalmente alaranjada (espécie isidiada) P. aurantiacoparvum

3. Medula amarelada clara a enxofre

4. Medula amarela clara; sem propágulos vegetativos P. cf. cryptoxanthoides

4. Medula amarela enxofre; com sorédios ou isídios

5. Talo sorediado (margens ciliadas) P. sorediosulphutarum

5. Talo isidiado

6. Margens eciliadas, medula com ácido secalônico, $\mathrm{K}+$ mais intensamente amarelado P. endosulphureum

6. Margens ciliadas, medula com ácido vulpínico, KP. sulphuratum 
Parmotrema aurantiacoparvum Sipman, Mycotaxon 44: 4. 1992. Tipo: GUIANA, Upper Mazuruni District, c. $2 \mathrm{~km} \mathrm{~S}$ de Waramadan, Sipman \& Aptroot 19186 (holótipo B).

Figuras 1a, b

Talo sublobado, verde-acinzentado claro a verde pardacento em herbário, de até $15,0 \mathrm{~cm}$ diâm., submembranáceo, ramulícola ou corticícola; lobos de ramificação irregular, 2,0-4,0 (-6,0) $\mathrm{mm}$ larg., sobrepostos lateralmente a raramente amontoados, adnatos a pouco adnatos, adpressos, ápices subarredondados a irregulares, planos a subplanos, margens lisas a crenadas principalmente quando isidiadas, planas a subplanas, superfície contínua a irregularmente quebrada, lisa a rugosa, às vezes quebradiça desprendendo pedaços em áreas submarginais muito isidiadas; lacínulas ausentes; máculas ausentes; cílios negros, simples, 0,20-2,60× ca. $0,05 \mathrm{~mm}$, abundantes ou ocasionalmente menos frequientes, surgindo por toda a margem. Sorais e pústulas ausentes. Isídios granulares a cilíndricos lisos, $0,05-2,30(-3,20) \times 0,05-0,10 \mathrm{~mm}$, simples ou em parte ramificados em estágios iniciais logo tornandose coralóides conforme se desenvolvem, eretos a pouco tortuosos ou raramente procumbentes, firmes a ocasionalmente caducos em partes quebradiças, concoloridos, surgindo nas margens às vezes tornandose também submarginais, e sobre os ápices de dobras do talo, parcial a comumente com ápices e lados ciliados, os cílios freqüentemente mais longos que os próprios isídios. Medula fortemente alaranjada, de cor mais acentuada nas partes jovens, toda pigmentada por uma antraquinona, podendo ocasionalmente despigmentar e tornar-se branca em áreas necrosadas ou expostas. Lado de baixo negro, lustroso, liso a pouco rugoso ou muito venado; margem marrom, lustrosa, 0,5-4,0 mm larg., atenuada, lisa a venada, raramente papilada, nua; rizinas concoloridas, de simples a raramente furcadas, 0,20-1,20 × ca. $0,05 \mathrm{~mm}$, poucas a freqüentes, homogeneamente distribuídas. Apotécios e picnídios não encontrados.

Testes de coloração e substâncias de importância taxonômica: córtex superior $\mathrm{K}+$ amarelo, UV(atranorina); medula $\mathrm{K}+$ vermelho muito escuro nas áreas pigmentadas, $\mathrm{K}-, \mathrm{C}-, \mathrm{KC}+$ róseo, $\mathrm{P}+$ alaranjado em áreas não pigmentadas, UV- (esquirina e um complexo de 4 a 6 substâncias UV+ púrpura vistas em $\mathrm{CCD}$ após borrifar $\mathrm{H}_{2} \mathrm{SO}_{2}$ ).
Distribuição: América do Sul. Brasil: PR e SP(Sipman \& Aubel 1992, Benatti 2005, Donha 2005).

Material estudado: BRASIL. SÃo PAUlo: Iguape, Barra do Ribeira, entre o "Rio" Suamirim e o oceano, mata de restinga baixa, 17-VII-1989, M.P. Marcelli \& $O$. Yano 6668 (SP); Ilha Comprida, parte sul da ilha, mata de restinga à beira da estrada próxima à balsa para Cananéia, 3-IV-2004, L.S. Canêz et al. 1235 (SP); idem, 3-IV-2004, L.S. Canêz et al. 1284; idem, mata de restinga à algumas centenas de metros da balsa, 3-IV-2004, M.N. Benatti et al. 1769 (SP); idem, IV2004, M.N. Benatti et al. 1775 (SP), idem, IV-2004, M.N. Benatti et al. 1779 (SP).

Parmotrema aurantiacoparvum difere muito das outras espécies de medula totalmente pigmentada do gênero. A medula é completamente impregnada com um pigmento alaranjado forte (um tipo de antraquinona), de reação $\mathrm{K}+$ vermelho muito escuro. Ocasionalmente, em alguns talos, foi possível observar áreas aleatórias não pigmentadas de cor branca, em partes velhas necrosadas ou expostas. Testes de coloração nestas partes reagem $\mathrm{KC}+$ róseo, $\mathrm{P}+$ alaranjado, similar às reações de ácido protocetrárico. Entretanto, esta substância não foi detectada em cromatografia, mas sim um complexo de substâncias desconhecidas que possivelmente sejam a causa desta reação.

Os espécimes menores encontrados se encaixam muito bem na descrição original (Sipman \& Aubel 1992), com isídios em parte ciliados que mal ultrapassam 0,3 mm altura. Entretanto, nos espécimes maiores os isídios alcançam mais de 3,0 mm de altura tornando-se muito ramificados, com cílios longos que chegam a ter de 3 a 5 vezes a altura de alguns isídios (visto claramente nos espécimes M.N. Benatti 1769 e 1779).

Os espécimes estudados por Sipman \& Aubel (1992) não ultrapassavam 4,0 cm diâm. Comparando sua descrição ao material do litoral, é possível crer que o autor tenha estudado um espécime muito jovem, parecido como alguns dos espécimes encontrados. Para esta afirmação também corrobora o descrito pelos autores e o observado aqui sobre a evolução do tamanho dos isídios e dos cílios nos espécimes mais desenvolvidos do litoral, sendo possível notar nestes espécimes todos os estágios. O espécime M.P. Marcelli 6668 é o que apresentou a menor quantidade de isídios ciliados, poucos se comparado aos demais espécimes estudados. 

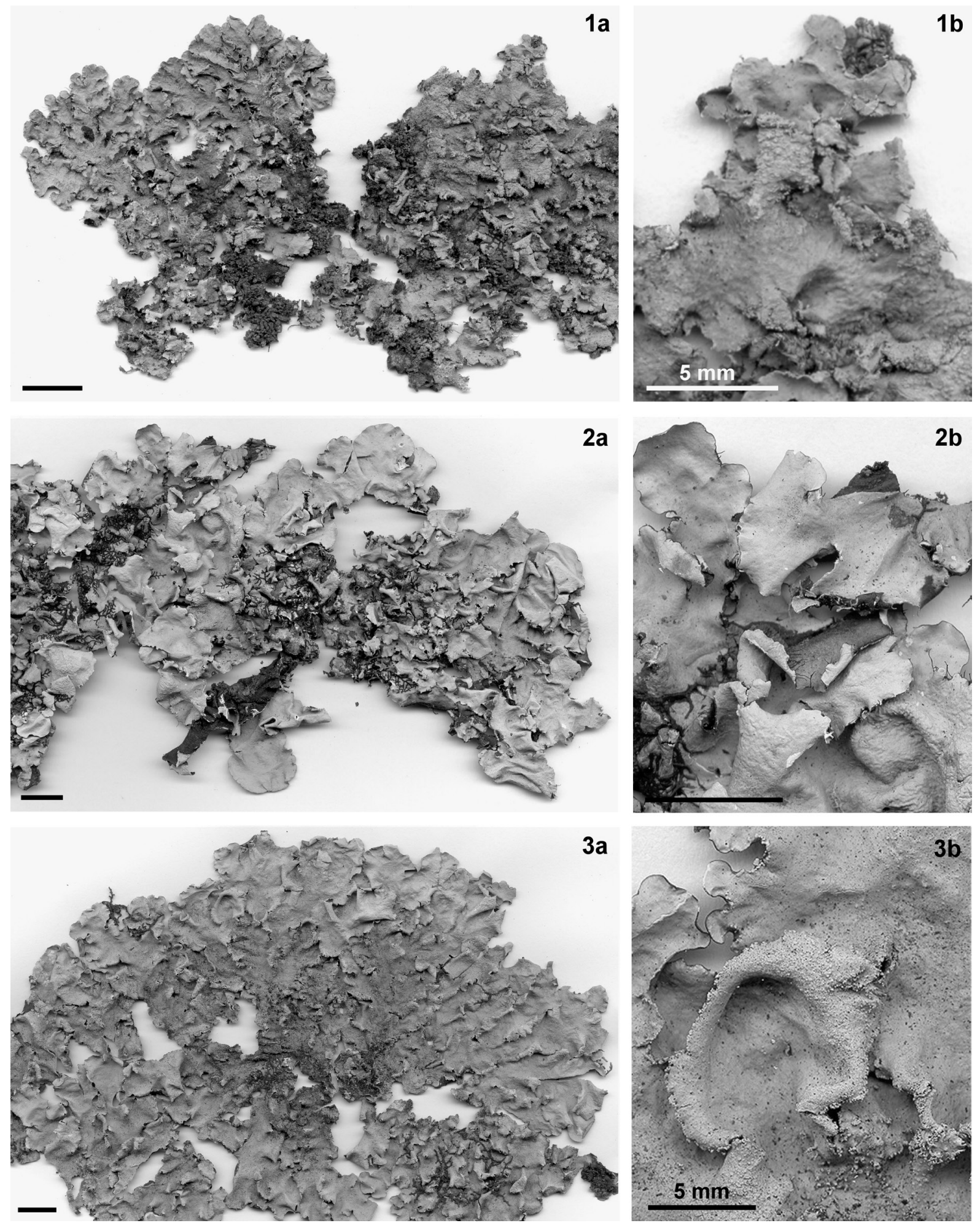

Figuras 1-3. Espécies de Parmotrema com medula pigmentada do litorl centro-sul do Estado de São Paulo. 1. Parmotrema aurantiacoparvum. a. Hábito. b. Detalhe (Marcelli 6668). 2. Parmotrema cf. cryptoxanthoides. a. Hábito. b. Detalhe (Marcelli 2383 ). Figura 3. Parmotema endosulphureum. a. Hábito. b. Detalhe (Marcelli 23756). Barras de escala $=1 \mathrm{~cm}$, exceto onde indicado.

Figures 1-3. Parmotrema species with pigmented medullae from São Paulo State center-south coastal areas. 1. Parmotrema aurantiacoparvum. a. Habit. b. Detail (Marcelli 6668). 2. Parmotrema cf. cryptoxanthoides. a. Habit. b. Detail (Marcelli 2383). 3. Parmotema endosulphureum. a. Habit. b. Detail (Marcelli 23756). Scale bars $=1 \mathrm{~cm}$, except when indicated. 
Kurokawa \& Moon (1998) discutiram as similaridades morfológicas entre $P$. hypomiltoides (Vainio) Kurokawa e P. aurantiacoparvum Sipman, sinonimizando esta com a primeira espécie. Seus apontamentos foram feitos com base no holótipo de $P$. hypomiltoides, que trata-se segundo os autores "de um fragmento pequeno e pobre". Os autores mencionaram que Sipman confirmou, através de uma comunicação pessoal, que o material visto por eles, proveniente do Estado de Pernambuco, Brasil, era quase idêntico ao material colombiano de P. aurantiacoparvum visto pelo próprio Sipman. Considerando a probabilidade de que o holótipo seja danificado e que Sipman tenha visto um espécime mal desenvolvido ou muito jovem de P. aurantiacoparvum ao descrever a espécie, é possível entender a provável confusão feita com $P$. hypomiltoides.

Na descrição original de Parmelia hypomiltoides Vainio, o autor é claro ao afirmar que a espécie é sorediada, sem formação de isídios, e que a medula é parcialmente pigmentada apenas em trechos visíveis do córtex inferior (Vainio 1890). O tamanho dos lobos descritos por ele é bem maior (5,0-10,0 mm larg.) que o observado nos espécimes de P. aurantiacoparvum, tanto nos de Sipman (1992) quanto nos observados neste estudo.

O material do litoral condiz bem com a descrição dos espécimes de $P$. aurantiacoparvum de Sipman (Sipman \& Aubel 1992), pois se tratam de espécimes isidiados e que não formam sorédios, e que têm medula totalmente pigmentada de cima a baixo, do centro às margens. Tal como Sipman comentou, lembram de certa forma o aspecto de espécimes de P. mellissii (Dodge) Hale, contudo não formando sorédios a partir dos isídios.

Ao mencionarem a comunicação de Sipman, Kurokawa \& Moon (1998) não disseram que ele confirmou a química dos espécimes de Pernambuco, e citaram a presença de ácidos alectorônico e $\alpha$-colatólico (KC+ róseo, UV+ azulado) em seu material de $P$. hypomiltoides. Essas substâncias não foram detectadas em nenhum espécime de $P$. aurantiacoparvum vistos por nós e também não foram mencionadas por Sipman (Sipman \& Aubel 1992) para seu material.

Portanto, com base nas diferenças da largura dos lobos, do tipo de propágulo, e de química medular vistas na comparação do material com as descrições de $P$. aurantiacoparvum e de $P$. hypomiltoides, é possível afirmar que certamente não se tratam da mesma espécie.
Parmotrema mellissii difere por formar isídios simples que se decompõem em sorédios, não ultrapassando 1,0 $\mathrm{mm}$ de altura, pela medula branca com manchas esparsas de pigmento alaranjado $\mathrm{K}+$, e pela presença de ácidos alectorônico e $\alpha$-colatólico medulares, que reagem $\mathrm{KC}+$ róseo e $\mathrm{UV}+$ azuladoesverdeado (Benatti 2005). Já $P$. endosulphureum (Hillmann) Hale e P. sulphuratum (Nees) Hale diferem pela medula consistentemente amarelo enxofre, e não alaranjada. A primeira é eciliada, contendo ácidos medulares do grupo secalônico, enquanto que a segunda é ciliada e contém ácido vulpínico medular. Nenhuma destas duas espécies tem isídios ciliados.

Parmotrema cf. cryptoxanthoides (Kurokawa) Hale ex DePriest \& B. Hale, Mycotaxon 67: 203.1998 = Parmelia cryptoxanthoides Kurokawa, Bulletin of the Natural Science Museum of Tokyo 17(4): 297. 1974. Tipo: BRASIL. Paraná: Jardim Paraíso, 9 km a oeste de Curitiba, Kurokawa 8245 (holótipo TNS).

Figuras 2a, b

Talo lobado, cinza esverdeado, pardo em herbário, até $17,0 \mathrm{~cm}$ diâm., submembranáceo, corticícola; lobos de ramificação irregular, (3,0-)6,0-16,0 mm larg., sobrepostos lateralmente tornando-se amontoados no centro do talo, adnatos a pouco elevados tornandose em parte pregueados e subcanaliculados, pouco adpressos, ápices arredondados a subarredondados, planos a subplanos, margens lisas a subcrenadas, pouco a não onduladas, planas a pouco elevadas, inteiras, de superfície contínua nas partes distais a irregularmente quebrada no centro, em geral bastante enrugada, principalmente em alguns lobos mais velhos do centro, lisa em algumas partes distais, às vezes quebradiça em alguns trechos; lacínulas ausentes, lóbulos jovens arredondados ou irregulares raramente aparecendo em partes velhas; máculas ausentes; cílios ausentes ou raros, de esparsos a pouco freqüentes em pequenos trechos das margens, 0,2-1,5 $\times$ ca. $0,05 \mathrm{~mm}$, simples, espalhados aleatoriamente por toda a margem. Sorédios e isídios ausentes. Pústulas verdadeiras ausentes, mas com rugas tortuosas laminais às vezes quebradiças, um tanto similares a pústulas que estivessem em estágios iniciais de desenvolvimento. Medula amarela muito clara, sem pigmentação alaranjada, tornando-se esbranquiçada em trechos expostos, ou branca (?) em alguns trechos aleatórios. Lado de baixo negro, lustroso, liso a pouco rugoso ou pouco venado, raramente papilado; margem 

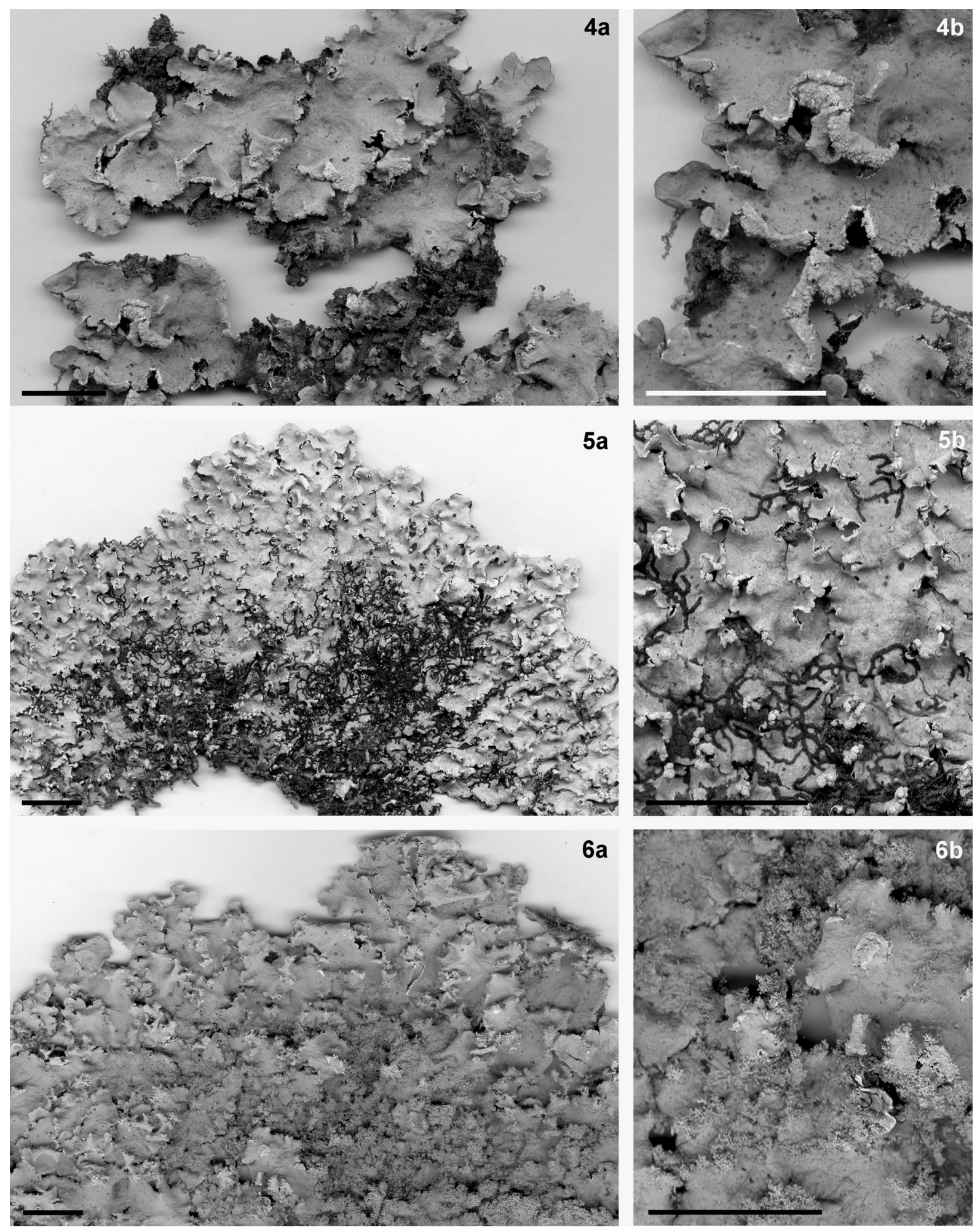

Figuras 4-6. Espécies de Parmotrema com medula pigmentada do litorl centro-sul do Estado de São Paulo. 4. Parmotrema sorediosulphuratum a. Hábito. b. Detalhe (Marcelli 36228). 5. Parmotrema subochraceum a. Hábito. b. Detalhe (Canêz 1275). 6. Parmotrema sulphuratum a. Hábito. b. Detalhe (Spielmann 558). Barras de escala $=1 \mathrm{~cm}$.

Figures 4-6. Parmotrema species with pigmented medullae from São Paulo State center-south coastal areas. Figure 4. Parmotrema sorediosulphuratum a. Habit. b. Detail (Marcelli 36228). Figure 5. Parmotrema subochraceum a. Habit. b. Detail (Canêz 1275 ). Figure 6. Parmotrema sulphuratum a. Habit. b. Detail (Spielmann 558). Scale Bars $=1 \mathrm{~cm}$. 
marrom clara a marrom, lustrosa, 2,0-10,0 mm larg., atenuada, lisa a pouco rugosa ou pouco venada, nua; rizinas concoloridas, simples, $0,20-0,80(-1,10) \times \mathrm{ca}$. $0,05 \mathrm{~mm}$, de poucas a freqüentes em alguns trechos, agrupadas. Apotécios não encontrados. Picnídios muito escassos, em meio a áreas muito enrugadas, ostíolo negro; conídios não encontrados.

Testes de coloração e substâncias de importância taxonômica: córtex superior $\mathrm{K}+$ amarelo, $\mathrm{UV}-$ (atranorina); medula $\mathrm{K}+$ amarelo claro, $\mathrm{C}+$ amarelo, $\mathrm{KC}+$ amarelo claro, $\mathrm{P}+$ amarelo pálido, UV- (ácidos caperático, liquesterínico, menegaziaico, outros três ácidos graxos não identificados em $\mathrm{CCD}$, e um pigmento desconhecido).

Distribuição: América do Sul. Brasil: PR e SP (Kurokawa 1974, Benatti 2005, Donha 2005).

Material estudado: BRASIL. São Paulo: Itanhaém, Rodovia Padre Manoel da Nóbrega (SP-55) km 108, cruzamento com o Rio Itanhaém, manguezal ao lado da rodovia, margem direita do rio, 10-I-1979, M.P. Marcelli \& L.R. Fontes 4 (SP) - parátipo de Parmotrema fumarprotocetraricum Marcelli \& Hale, inadvertidamente citado por Hale (1986) no protólogo desta espécie; idem, 1-IV-1988, M.P. Marcelli \& L.R. Fontes 2383 (SP).

O material encontrado no litoral de SP apresenta algumas dúvidas, como o fato de a medula ser talvez parte esbranquiçada em alguns trechos, sendo que também não foram encontrados apotécios ou conídios, mas que podem se tratar de espécimes pouco desenvolvidos de P. cryptoxanthoides. Nenhuma outra descrição de espécie vista em literatura aproximou-se mais do conjunto de características encontrado.

Conforme mencionou Kurokawa (1974), e de acordo com o que foi observado no material aqui estudado, P. cryptoxanthoides caracteriza-se pelo talo submembranáceo, de superfície distintamente rugosa com partes quebradiças (especialmente em lobos velhos), medula amarelo muito clara e cílios ausentes a muito esparsos, com até $1,5 \mathrm{~mm}$ de comprimento (na descrição original com até $2,5 \mathrm{~mm}$ ). A medula apresenta uma tonalidade amarelada clara, que parece ocorrer ao menos na maior parte de sua extensão.

Conforme dito, não há apotécios nos espécimes deste trabalho, além de não terem sido encontrados conídios em nenhum dos pouquíssimos picnídios vistos no material. Donha (2005) citou conídios sublageniformes medindo $7,0-8,0 \times 1,0 \mu \mathrm{m}$. A descrição original da espécie (Kurokawa 1974) não menciona conídios, mas menciona ascósporos $(22,0-$ $27,0 \times 10,0-12,0 \mu \mathrm{m})$.

Kurokawa (1974) diferenciou P. cryptoxanthoides de $P$. cryptoxanthum (Abbayes) Hale mencionando que $a$ primeira nunca tornava-se sorediada ou verdadeiramente pustulada, enquanto que as verrucosidades vistas em $P$. cryptoxanthum com frequiência rompiam formando sorédios granulares nos ápices de lobos. Os cílios descritos para $P$. cryptoxanthum são mais densos e mais longos (3,0 mm compr. ou mais) e a medula é pigmentada de amarelo apenas em parte da medula, e não em toda ela, como normalmente ocorre em $P$. cryptoxanthoides.

Em ambas as espécies são conhecidas a produção de ácidos graxos. Entretanto, Kurokawa (1974) comentou que cristais observados em solução G.E. de $P$. cryptoxanthoides eram similares aos de ácido caperático (em CCD foi vista uma substância que provavelmente trata-se de ácido caperático), enquanto que os de $P$. cryptoxanthum eram similares aos do ácido protoliquesterínico, (em CCD encontraram-ses também outros ácidos, um aparentemente sendo ácido liquesterínico, outro ácido menegaziaico, e outros três ácidos graxos não identificados).

Parmotrema cornutum (Lynge) Hale difere segundo a descrição de Hale (1965) por ter córtex íntegro, com medula amarelo limão (cor forte e brilhante, devido ao ácido vulpínico), margem dos lobos e dos apotécios denteado-lacinulada, apotécios ciliados com ascósporos maiores que os citados por Kurokawa (1974) para P. cryptoxanthoides $(26,0-32,0$ $\times 22,0-27,0 \mu \mathrm{m})$.

Parmotrema lyngeanum (Zahlbruckner) Hale difere segundo Hale (1974b) pela medula bicolor, amarelo clara na parte superior e avermelhada no lado de baixo (respectivamente pela presença de entoteína e de rodoficina). Zahlbruckner (1930) havia renomeado Parmelia merrillii de Lynge como Parmelia lyngeana (= Parmotrema lyngeanum), ao descobrir que a espécie havia sido publicada como um sinônimo nomenclatural, pois já havia na época uma espécie de nome Parmelia merrillii publicada por Vainio (1909). A descrição original de P. merrillii Lynge (1914) cita lobos bem mais estreitos (5,0-6,0 $\mathrm{mm}$ ) que os observados em $P$. cryptoxanthoides.

Existe pouca referência bibliográfica para $P$. appendiculatum (Fée) Hale, sendo que Hale (1965) sinonimizou Parmelia merrillii de Lynge [i.e., Parmelia lyngeana Zahlbruckner/ Parmotrema lyngeanum (Zahlbruckner) Hale, não Parmelia 
merrillii Vainio 1909] nesta espécie, uma vez que $P$. appendiculatum também é caracterizada por ter uma medula bicolor, semelhante à de P. lyngeanum: branco a amarelo claro na parte superior e alaranjado no lado de baixo, porém com entoteína e ácido barbático, ao invés de rodoficina.

Parmotrema appendiculatum tem ainda margens evidentemente lacinuladas e apotécios denteadolacinulados ciliados, como os que são citados para $P$. cornutum. Retirando-se os sinônimos colocados em $P$. appendiculatum, esta espécie é ainda desconhecida do neotrópico. É provável que estes sinônimos necessitem serem revistos.

Parmotrema endosulphureum (Hillmann) Hale, Phytologia 28(4): 336.1974 三 Parmelia tinctoria var. endosulphurea Hillmann. Feddes Repertorium specierum novarum regni vegetabilis 48: 8. 1940. Tipo: MEXICO, Orcutt 4728 (holótipo MO).

Figuras $3 \mathrm{a}, \mathrm{b}$

Talo lobado, verde acinzentado a pardo claro quando em herbário, até $19,5 \mathrm{~cm}$ diâm, subcoriáceo a coriáceo, corticícola ou saxícola; lobos de ramificação irregular, (2,5-)4,0-14,0 mm larg., contíguos a pouco sobrepostos lateralmente, tornando-se às vezes um pouco amontoados no centro, adnatos a pouco elevados, moderadamente adpressos, às vezes tornando-se pregueados e subcanaliculados nas margens laterais, ápices arredondados a subarredondados, subplanos a ocasionalmente subcôncavos, margens lisas ou às vezes subcrenadas pelo surgimento de isídios, subplanas a subonduladas, ascendentes e involutas, inteiras, superfície contínua ou com poucas quebras que ficam mais acentuadas nas partes velhas, lisa a subrugosa; lacínulas ausentes, lóbulos às vezes aparecendo em partes velhas, simples, arredondados, subplanos a subcôncavos, de lado de baixo concolorido à margem inferior; máculas ausentes; cílios ausentes . Sorédios e pústulas ausentes. Isídios granulares a cilíndricos lisos, 0,05-0,60 × ca. 0,05 mm, simples a pouco ramificados ou mais raramente tornando-se coralóides, eretos, retos a tortuosos, normalmente firmes a ocasionalmente caducos em alguns trechos, concoloridos ou quando jovens de ápices marrons, eciliados, comuns em ápices de dobras passando a laminais, ou marginais em lobos mais velhos. Medula amarela enxofre clara nas partes mais jovens, tornandose gradativamente mais escura em direção ao centro do talo, sem outras pigmentações do tipo $\mathrm{K}+$. Lado de baixo negro, lustroso, liso a pouco venado ou pouco rugoso, às vezes papilado na transição com a margem, com trechos rizinados e outros não; margem marrom, lustrosa, 1,5-6,0(-10,0) $\mathrm{mm}$, atenuada, lisa a venada, nua; rizinas normalmente concoloridas, às vezes de cor creme ou branca próximas da margem, simples, 0,10-1,00 × ca. $0,05(-0,10) \mathrm{mm}$, freqüentes tornandose mais abundantes nas partes centrais, agrupadas. Apotécios cupuliformes a unciformes, 0,6-5,2 mm diâm., laminais a submarginais, subpedicelados quase adnatos, a margem lisa a crenada pela formação de isídios, isidiada, o anfitécio e o pedicelo rugosos e venados muito isidiados e em alguns dos apotécios mais jovens ficando ocultados pelos isídios em certas partes do talo; disco marrom, ausente nos apotécios mais velhos, não pruinoso, imperfurado; ascósporos não encontrados. Picnídios submarginais, de ostíolo negro; conídios sublageniformes ou bifusiformes, 4,0-6,0 × ca. $1,0 \mu \mathrm{m}$.

Testes de coloração e substâncias de importância taxonômica: córtex superior $\mathrm{K}+$ amarelo, $\mathrm{UV}+$ somente nos ápices dos lobos (atranorina); medula $\mathrm{K}+$, $\mathrm{C}+\mathrm{e} \mathrm{KC}+$ mais intensamente amarelados, $\mathrm{P}-$ (torna medula branca), UV- (três ácidos do grupo secalônico, provavelmente $\mathrm{A}$ e $\mathrm{C}$ e um desconhecido, ácidos graxos e em CCD duas substâncias desconhecidas $\mathrm{UV}+$ antes e após borrifo com $\mathrm{H}_{2} \mathrm{SO}_{2}$. Não foram encontrados traços de ácido girofórico).

Distribuição: Ásia, África, América do Norte, América Central, Caribe, América do Sul. Brasil: BA, RJ, RS e SP (Hale 1965, 1974b, Benatti 2005, Donha 2005).

Material estudado: BRASIL. SÃo PAulo: Bertioga, Prainha Branca, rocha granítica úmida à beira mar, 21-VIII-1979, M.P. Marcelli \& A.E. Luchi 16428 (SP). Iguape, Barra do Ribeira, entre o "Rio" Suamirim e o oceano, mata de restinga baixa com solo encharcado, 17-VII-1989, M.P. Marcelli \& O. Yano 6591 (SP). Itanhaém, manguezal no cruzamento do Rio Itanhaém com a rodovia Manoel da Nóbrega, margem direita do rio, 1-IV-1988, M.P. Marcelli \& L.R. Fontes 2397 (SP). Peruíbe, Reserva Ecológica Juréia-Itatins, Núcleo Guarauzinho, no sopé da Serra do Mar, ao redor da sede, 26-VII-1993, M.P. Marcelli \& O. Yano 23699 (SP); idem, Praia do Arpoador, lado sul da praia, 27-VII-1993, M.P. Marcelli \& O. Yano 23713 (SP); idem, Praia do Arpoador, lado esquerdo da desembocadura do Córrego da Água Fria, ao lado da sede, 28-VII-1993, M P. Marcelli \& O. Yano 23756 (SP); idem, 28-VII-1993, M.P. Marcelli \& O. Yano 
23761 (SP). Praia Grande, Bairro Cidade Ocean, ca. $1 \mathrm{~km}$ após a estátua de Iemanjá, $2 \mathrm{~km}$ da de Netuno, em direção a Mongaguá, terreno entre o oceano e a estrada separado da praia por uma lagoa inter-dunas com resíduo de vegetação de duna posterior e mata de restinga, 31-III-1988, M.P. Marcelli \& L.R. Fontes 2352 (SP). Ubatuba, Ilha Anchieta, mata de restinga, próximo ao arroio no interior da mata de restinga, 22-XII-2003, L.S. Canêz \& A.A. Spielmann 646 (SP); idem, 22-XII-2003, L.S. Canêz \& A.A. Spielmann 650 (SP).

Parmotrema endosulphureum é caracterizada pelos lobos relativamente largos e arredondados, ausência de cílios marginais, isídios principalmente laminais, e medula totalmente de coloração amarela enxofre. Seu hábito é muito semelhante ao de Parmotrema tinctorum (Nylander) Hale, sendo que até ter ocorrido a mudança de status para espécie por Hale (1965), Parmelia endosulphurea (= Parmotrema endosulphureum) era até então considerada como uma variedade de Parmelia tinctoria (= Parmotrema tinctorum).

Embora semelhante na morfologia a P.tinctorum, P. endosulphureum apresenta talos em geral mais planos. Outra diferença entre as duas espécies está na química medular: $P$. tinctorum tem a medula uniformemente branca sem nenhum indício de pigmentos, contendo ácido girofórico, $\mathrm{C}+\mathrm{e} \mathrm{KC}+$ avermelhados (Benatti 2005).

A ocorrência de traços de ácido girofórico medular em P. endosulphureum é mencionada por Donha (2005), e também é um caráter utilizado na chave de M.E. Hale revisada por Sipman (2004) para as espécies de Parmotrema e gêneros relacionados na América tropical.

Entretanto, a descrição de Hale (1965) não menciona a ocorrência desta substância, que também não foi detectada no material de $P$. endosulphureum estudado aqui, tanto nos testes de coloração como em CCD. Assim como mencionou o autor, os testes de coloração apenas realçam a coloração da medula, tornando-a mais intensa porém sem mudar para outra coloração, enquanto que num artigo posterior (Hale 1974b) o autor mencionou que a composição química da espécie havia sido esclarecida, englobando então atranorina, ácido girofórico, entoteína (um ácido secalônico) e compostos associados.

Foi observada sobre a incidência de luz UV nos espécimes estudados de $P$. endosulphureum uma fluorescência alaranjada clara nos lobos e lóbulos jovens (principalmente os mais distais). Não foi possível esclarecer se a coloração vista sobre luz UV era de fato causada por uma ou mais das substâncias não identificadas em cromatografia, embora fossem fluorescentes e apresentassem similaridade de coloração sobre luz UV, e possam talvez estarem de fato relacionadas.

Parmotrema sulphuratum (Nees \& Flotow) Hale difere pelos lobos mais estreitos (ca. 2,0-6,0 mm), margens ciliadas, isídios maiores e mais ramificados com 1,0-2,0 mm alt. (Hale 1965 mencionou isídios com até 3,0 $\mathrm{mm}$ alt.), medula amarelo-enxofre mais forte e escura (ácido vulpínico) que não reage a testes de coloração e que não acentuam a coloração da medula como em $P$. endosulphureum, e rizinas mais homogeneamente distribuídas.

Parmotrema aurantiacoparvum Sipman difere por ter margens ciliadas e isídios bastante ramificados e ciliados com cílios longos. Em P. aurantiacoparvum a medula é alaranjada forte devido à presença de pigmento K+ vermelho escuro (antraquinona), ao invés de substâncias amareladas como ácidos secalônicos ou vulpínico (ver outros comentários sobre as diferenças entre as espécies isidiadas de medula colorida nas descrições de P.aurantiacoparvum e P. sulphuratum).

Parmotrema permutatum (Stirton) Hale, Phytologia 28(4): 338.1974 = Parmelia permutata Stirton, Scottish Naturalist 4: 252. 1877-78. Tipo: AUSTRÁLIA. Próximo à Brisbane, Bailey 25 (lectótipo BM!, isolectótipo GLAM!).

Esta espécie foi previamente abordada em Benatti \& Marcelli (2009), junto ao grupo de espécies caracterizado por conter ácidos girofórico ou lecanórico medulares.

Parmotrema permutatum é caracterizada pela medula com camadas de cores diferentes (branca na parte superior, tendo logo abaixo uma camada pigmentada de múltiplas cores na metade inferior), margens ciliadas, sorais marginais lineares ou nos ápices de lacínulas, e rizinas simples e agrupadas no córtex inferior. Uma ilustração pode ser vista em Benatti \& Marcelli 2009, figura 5a-b.

Parmotrema sorediosulphuratum Eliasaro \& Donha, Mycotaxon 95: 242. 2006. Tipo: BRASIL. PARANÁ: Antonina, Chácara Donha, 2514'31'S, 4844'49"W, 29-IX-2004, C.G. Donha 1808 (holótipo UPCB).

Figuras 4a, b 
Talo lobado a sublobado, verde acinzentado a verde pardacento quando em herbário, até 9,5 cm diâm., submembranáceo, corticícola; lobos de ramificação irregular, (1,5-) 3,0-9,5 mm larg., contíguos a pouco sobrepostos lateralmente ou raramente pouco amontoados no centro do talo, adnatos, adpressos, ápices subarredondados, de planos a subplanos, margens lisas a crenadas pelo surgimento de sorédios granulares (similares a primórdios de isídios), retas a subonduladas, planas a subascendentes e involutas, inteira, superfície contínua, com poucas quebras em áreas mais velhas, lisa a pouco rugosa; lacínulas ausentes, raramente surgindo alguns poucos lóbulos adventícios em partes velhas, simples, subarredondados, subplanos, lado de baixo concolorido à margem inferior; máculas ausentes; cílios negros, simples ou às vezes furcados, 0,20$1,80 \times$ ca. $0,05 \mathrm{~mm}$, marginais escassos em alguns trechos, tornando-se gradativamente mais freqüentes próximos às axilas dos lobos. Sorais marginais ou submarginais, em parte agregando e tornandose irregulares, raramente adquirindo um aspecto linear interrompido breve; sorédios subgranulares a granulares, às vezes parecendo com isídios granulares em início de formação, originados de sorais. Pústulas e isídios ausentes (ver descrição dos sorédios). Medula amarela forte, brilhante, pouco mais clara nas partes distais, com pigmentações do tipo $\mathrm{K}+\mathrm{em}$ alguns pontos, porém não discerníveis devido a forte coloração amarela. Lado de baixo negro, lustroso, liso a venado, parte papilado, com trechos rizinados e outros não; margem marrom a marrom clara, às vezes variegada, lustrosa a opaca, 1,5-3,5 mm larg., atenuada, lisa a pouco venada ou pouco rugosa, às vezes papilada na área de transição para o centro, nua; rizinas concoloridas, simples ou às vezes furcadas, 0,10-1,20 × ca. $0,05 \mathrm{~mm}$, escassas tornando-se mais freqüentes em alguns trechos, agrupadas, esparsas. Apotécios e picnídios não encontrados.

Testes de coloração e substâncias de importância taxonômica: córtex superior $\mathrm{K}+$ amarelo, UV(atranorina); medula $\mathrm{K}-(\mathrm{K}+$ alaranjado forte em alguns pontos), $\mathrm{C}-, \mathrm{KC}-, \mathrm{P}-, \mathrm{UV}-$ (ácido vulpínico e um ácido graxo detectado em CCD. Deve haver uma pequena quantidade de pigmento $\mathrm{K}+$ na medula, imperceptível devido à forte coloração amarela-enxofre. Este pigmento não foi detectado em cromatografia, mas em certos pontos ao se depositar $\mathrm{K}$ insistentemente é possível observar uma reação alaranjada forte.
Distribuição: América do Sul. Brasil: PR e SP (Benatti 2005, Donha 2005, Donha \& Eliasaro 2006).

Material estudado: BRASIL. São PAUlo: Itanhaém, Estância Santa Cruz (Bairro em formação), próximo à divisa de municípios entre Itanhaém e Peruíbe, ca. 300m do mar, mata de restinga baixa, 10-II-2004, M.P. Marcelli et al. 36228 (SP).

Segundo Donha (2005) e Donha \& Eliasaro (2006), P. sorediosulphuratum é o par sorediado de $P$. sulphuratum (Nees) Hale, ambas tendo como espécie parental $P$. cornutum (Lynge) Hale. A espécie é caracterizada pelo talo aplanado, com margens sorediadas e ciliadas, medula amarelo enxofre forte e brilhante e córtex inferior com rizinas simples agrupadas. Aparentemente, nosso espécime difere do material do Paraná apenas pela menor freqüência de rizinas e de cílios.

Entre as características mencionadas por Donha (2005), são notáveis as projeções de aspecto isidióide que surgem nas margens, que na verdade tratam-se de sorédios granulares que se formam inicialmente um pouco distantes uns dos outros. Não foram encontrados em nosso material e nem são citados pela autora sorais de aspecto isidióide ou isídios verdadeiros que pudessem originar sorédios por dissolução, como ocorrem, por exemplo, em P. mellissii (Dodge) Hale.

Conforme vão aumentando, os pequenos sorais marginais vão aglomerando tornando-se mais irregulares, passando também em parte a submarginais, e sua origem a partir da formação de sorédios passa a ser mais facilmente discernível. É perceptível que sorédios laminais surjam por uma aparente dissolução do córtex, em início sendo corticados (grânulos) e sem a forte coloração amarela mais evidente nos sorais marginais.

Foi possível notar que ao colocar insistentemente reagente $\mathrm{K}$ em certos pontos da medula, se desenvolvia uma reação forte alaranjada, parecida com a reação esperada para pigmentos do tipo antraquinonas. Entretanto, estes pigmentos não foram visualizados com clareza, e também não foi possível detectá-los em cromatografia. A corrida cromatográfica de $P$. sorediosulphuratum foi praticamente idêntica à de sua contraparte isidiada, P. sulphuratum.

Parmotrema hypomiltoides (Vainio) Kurokawa (Hale 1965, Fleig 1997, Kurokawa \& Moon 1998) aproxima-se de $P$. sorediosulphuratum no aspecto dos sorais, inclusive pelo formato isidióide que eventualmente adquirem pela superposição dos sorédios, entretanto $P$. hypomiltoides tem medula 
parcial a totalmente pigmentada apenas na porção inferior, segundo Fleig (1997) com pigmento alaranjado $\mathrm{K}+$ vermelho escuro ou $\mathrm{K}+$ púrpura. Segundo estes autores, $P$. hypomiltoides apresenta ainda ácidos alectorônico e $\alpha$-colatólico medulares (KC+ róseo, UV+ azul-esverdeado).

Parmotrema permutatum (Stirton) Hale também difere pela medula bicolor, com a porção inferior pigmentada de múltipla coloração, e apresenta ácido girofórico medular ( $\mathrm{C}+\mathrm{e} \mathrm{KC}+$ róseo a avermelhado) além da pigmentação. Outra diferença é o formato e disposição dos sorais que são mais restritos às margens sendo mais lineares, com sorédios de granulação mais fina similares aos de espécies como P. sancti-angeli (Lynge) Hale.

Parmotrema araucariarum (Zahlbruckner) Hale difere pela coloração mais clara da medula, devido à pigmentação por ácidos secalônicos como entoteína, do mesmo tipo que a encontrada em $P$. endosulphureum $(\mathrm{C}+$ realça a coloração, tornando-a amarelada mais forte), pelas margens eciliadas ou muito raramente com cílios esparsos muito curtos (Hale 1965, 1974b). Como em P. permutatum, os sorais em $P$. araucariarum tendem também a serem mais lineares.

Parmotrema subochraceum Hale, Bibliotheca Lichenologica 38: 117. 1990. Tipo: BRASIL. PARÁ: Serra do Cachimbo, Cataratas do Rio Curuá, 877 km N de Cuiabá na Rodovia Cuiabá-Santarém, Brako \& Dibben 6506 (holótipo NY, isótipo US).

Figuras 5a, b

Talo lobado a sublobado, de cinza esverdeado claro a cinza esverdeado pardo quando em herbário, até $13,5 \mathrm{~cm}$ diâm., membranáceo a submembranáceo, corticícola ou ramulícola; lobos de ramificação irregular, (1,5-)2,0-7,0(-10,5) mm larg., contíguos a pouco sobrepostos lateralmente, adnatos a pouco adnatos tornando-se mais elevados em direção ao centro conforme ficam sorediados, adpressos a pouco adpressos, ápices subarredondados, planos a subplanos, margens lisas a parcialmente subcrenadas, subplanas a subascendentes, retas a subonduladas às vezes tornando-se involutas quando sorediadas, inteiras a pouco incisas, frequientemente sublacinuladas, superfície contínua e lisa nas partes distais tornando-se irregularmente quebrada e subrugosa em algumas partes do centro; lacínulas marginais adventícias irregularmente distribuídas, mais freqüentes em direção ao centro, misturadas ocasionalmente com lóbulos irregulares, planas a raramente subcanaliculadas, $0,3-1,8 \times 0,2-0,8(-1,4)$ $\mathrm{mm}$, normalmente simples, agudas ou truncadas, lado de baixo concolorido à margem inferior ou creme quando em lobos sorediados. Máculas fracas a distintas, laminais ocasionais geralmente limitadas a lobos jovens, lineares; cílios ausentes ou muito raros, simples, negros, $0,10-0,60 \times 0,05 \mathrm{~mm}$, marginais esparsos ou nas axilas dos lobos. Sorais marginais subcapitados a lineares interrompidos ou nos ápices de lacínulas muito curtas, parcialmente coalescentes e irregulares, às vezes estendendo-se submarginais ou soerguendo ( \pm arbusculares), raramente surgindo também como subcapitados laminais; sorédios subgranulares. Pústulas e isídios ausentes. Medula branca, com pigmentação alaranjada $\mathrm{K}+$ avermelhado escuro em hifas distintas, entrelaçadas com as hifas brancas, visíveis total a parcialmente na porção inferior da medula, às vezes formando manchas. Lado de baixo negro, lustroso, liso a subrugoso, às vezes papilado; margem marrom, tornando-se creme ou branca em lobos sorediados, lustrosa, 0,5-3,5 mm larg., atenuada quando marrom a nítida quando creme ou branca, lisa às vezes pouco papilada, nua; rizinas concoloridas, às vezes marrons ou de ápices brancos próximas às margens, simples ou raramente furcadas, 0,10-1,10 $\times$ ca. $0,05(-0,10) \mathrm{mm}$, normalmente freqüentes, variando de pouco mais escassas em alguns trechos a mais densas nas partes centrais, distribuídas quase homogeneamente. Apotécios côncavos, 0,5-3,1 mm diâm, laminais a submarginais, subpedicelados a sésseis, margem inicialmente lisa tornando-se sorediada, anfitécios e pedicelos lisos inicialmente lisos tornando-se subrugosos e sorediados; disco marrom, não pruinoso, imperfurado; ascósporos elipsóides, 19,0-30,5 × 11,0-16,5 $\mu \mathrm{m}$, epispório 2,02,5 um. Picnídios não encontrados.

Testes de coloração e substâncias de importância taxonômica: córtex superior $\mathrm{K}+$ amarelo, $\mathrm{UV}-$ (atranorina); medula $\mathrm{K}-, \mathrm{C}-, \mathrm{KC}+$ róseo, $\mathrm{P}+$ alaranjado, UV- (ácidos protocetrárico, traços de succinprotocetrárico, em alguns espécimes traços aparentemente de ácidos liquesterínico e divaricático, e presença constante de pigmento desconhecido alaranjado e K+ avermelhado escuro do tipo antraquinona em hifas e manchas visíveis na porção inferior).

Distribuição: América do Sul. Guianas e Brasil: PA, PR e SP (Hale 1990, Benatti 2005, Donha 2005, Feuerer 2005, Jungbluth 2006). 
Material estudado: BRASIL. São Paulo: Cananéia, Ilha do Cardoso, Praia do Pereirinha, às margens do Rio Perequê, manguezal perto da base, 21-X-1981, M.P. Marcelli 1570 (SP). Ilha Comprida, próximo à balsa para Cananéia, mata de restinga, 2-IV-2004, A.A. Spielmann et al. 803 (SP); idem, 4-IV-2004, A.A. Spielmann et al. 1011 (SP); idem, 2-IV-2004, L.S. Canêz et al. 1320 (SP); idem, 2-IV-2004, L.S. Canêz et al. 1330 (SP); idem, 2-IV-2004, L S. Canêz et al. 1338 (SP); idem, 2-IV-2004, L S. Canêz et al. 1329 (SP); idem, 2-IV-2004, L.S. Canêz et al. 1331 (SP); idem, 2-IV-2004, L S. Canêz et al. 1349 (SP); idem, na beira da estrada próximo à balsa para Cananéia, 3-IV-2004, L.S. Canêz et al. 1224 (SP); idem, 3-IV2004, L.S. Canêz et al. 1245 (SP); idem, 3-IV-2004, L.S. Canêz et al. 1275 (SP); idem, no interior da mata, 03-IV-2004, L.S. Canêz et al. 1263 (SP). Itanhaém, manguezal na foz do Rio Itanhaém, próximo à ponte antiga na Rodovia Padre Manoel da Nóbrega (SP-55) $\mathrm{km}$ 108, na margem direita do rio, 10-I-1979, M P. Marcelli \& L R. Fontes 1575 (SP); idem, 10-I-1979, M.P. Marcelli \& L.R. Fontes 1579 (SP); idem, 1-IV1988, M.P. Marcelli \& L.R. Fontes 2391 (SP); idem, 21-VIII-1995, M.P. Marcelli et al. 29383 (SP); idem, 15-X-2003, M.I. Käffer et al. s.n. (3 coletas, SP); idem, 15-X-2003, A.A. Spielmann et al. 538 (SP); idem, 15X-2003, L.S. Canêz et al. 531 (SP); idem, 15-X-2003, M.N. Benatti et al. 1687 (SP); idem, Balneário Santa Cruz, próximo à divisa de municípios entre Itanhaém e Peruíbe, mata de restinga baixa a ca. $500 \mathrm{~m}$ da praia, terrenos baldios em área sendo loteada, 14-I-2004, M.N. Benatti et al. 1696 (SP); idem, 14-I-2004, M.N. Benatti et al. 1701 (SP); idem, 14-I-2004, M.N. Benatti et al. 1709 (SP); idem, 14-I-2004, M.N. Benatti et al. 1721 (SP); idem, ca. $300 \mathrm{~m}$ do oceano, mata de restinga baixa, 10-II-2004, M.P. Marcelli et al. 36212 (SP). Mongaguá, próximo à estação de tratamento de água da SABESP, mata de restinga baixa ao lado da estrada de areia para o Rio Bichoró, ca. 100 m do rio, 16-XII-2003, M.N. Benatti et al. 1659 (SP); idem, 16-XII-2003, M.N. Benatti et al. 1663 (SP); idem, 16-XII-2003, M.N. Benatti et al. 1671 (SP); idem, 16-XII-2003, M.N. Benatti, et al. 1676 (SP); idem, 16-XII-2003, M.N. Benatti et al. 1677 (SP). Peruíbe, Praia de Itanhaém, na divisa de municípios entre Itanhaém e Peruíbe, entre a rodovia e o oceano, mata de restinga a ca. $500 \mathrm{~m}$ do mar, 30-VI-1981, M.P. Marcelli \& A. Mathey 1235 (SP); idem, Balneário Santa Cruz, na divisa de municípios entre Itanhaém e Peruíbe, mata de restinga baixa em área loteada a ca. de $500 \mathrm{~m}$ da praia, 16-XII-2003, M.N. Benatti et al. 1682 (SP); idem, 16-XII-2003, M.N. Benatti et al. 1683 (SP). Praia Grande, Bairro Cidade Ocean, ca. 1 km após a estátua de Iemanjá, 2 km da de Netuno, em direção à Mongaguá, terreno entre praia e a estrada com resíduo de vegetação de duna posterior e mata de restinga, 4-VII-1988, M.P. Marcelli \& J. Vieira Filho 3019 (SP); idem, 4-VII-1988, M.P. Marcelli \& J. Vieira Filho 3021A (SP); idem, 4-VII-1988, M.P. Marcelli \& J. Vieira Filho 3059 (SP).

Para uma espécie tão facilmente coletada na área de estudo, é estranho que haja somente três menções em literatura (Hale 1990, Donha 2005, Jungbluth 2006). Parmotrema subochraceum é caracterizada pelo talo membranáceo, sorais marginais lineares ou subcapitados em ápices de lacínulas curtas, margens eciliadas a esparsamente ciliadas, e medula contendo ácido protocetrárico $(\mathrm{KC}+$ róseo, $\mathrm{P}+$ alaranjado, $\mathrm{UV}-$ ) e um pigmento alaranjado $\mathrm{K}+$ vermelho escuro constante.

Alguns espécimes observados tinham apotécios sorediados, contendo ascósporos de tamanhos semelhantes aos citados por Donha (2005) para o estado do Paraná $(20,0-25,0 \times 12,5-15,0 \mu \mathrm{m})$. A largura dos lobos do material aqui estudado está mais de acordo com a mencionada por Hale (1990) na descrição original da espécie (3,0-6,0 mm), enquanto que Donha (2005) menciona lobos com larguras máximas maiores $(3,0-9,0 \mathrm{~mm}$, eventualmente com até $12,0 \mathrm{~mm}$ ). Hale não mencionou ascósporos ou conídios.

Todos os espécimes estudados apresentaram uma forma peculiar de pigmentação na porção inferior da medula: o pigmento ocorre em hifas alaranjadas distintas, entrelaçadas com as demais hifas brancas que compõem a maior parte da medula do talo. Isto é bem distinto das demais espécies pigmentadas de Parmotrema, em que a medula varia de parcialmente a totalmente impregnada por pigmento, como em P.permutatum (Stirton) Hale ou P. aurantiacoparvum Sipman, ou das espécies que mostram casualmente pequenas manchas, como P. mellissii (Dodge) Hale.

Raras vezes manchas são percebidas nos espécimes de $P$. subochraceum, mas é possível notar que algumas hifas pigmentadas têm a coloração ainda mais forte que a da mancha, indicando aparentemente que o pigmento deve se dispersar a partir destas hifas e manchando as brancas adjacentes, por algum motivo desconhecido.

Este padrão de pigmentação das hifas não foi mencionado nas descrições de Hale (1990) e 
Donha (2005), que se referiram somente à presença do pigmento junto ao córtex inferior. Como na descrição de ambos os autores, o material aqui examinado tem talos membranáceos e eciliados (ou às vezes esparsamente ciliados), e não foi encontrada outra espécie na área de estudo com as mesmas características e com pigmentação do mesmo tipo na parte de baixo da medula.

O padrão de pigmentação das hifas em $P$. subochraceum varia apenas na amplitude com que se espalha pela medula, sendo que em alguns talos as hifas coloridas estão mais restritas a alguns trechos, enquanto que em outros se espalha por toda a porção inferior. Isto pode fazer com que quando não muito disperso, a aparente ausência do pigmento num determinado local onde o córtex foi removido para visualização leve um observador a crer que possa tratar-se de outra espécie.

Foram encontrados traços de dois ácidos graxos em alguns dos espécimes em CCD, supostamente ácidos liquesterínico e divaricático. Estas substâncias não são mencionadas nos dois trabalhos onde $P$. subochraceum foi mencionada, podendo talvez se tratar de uma contaminação da amostra. Foi notado também em cromatografia que os traços de ácido succinprotocetrárico, embora freqüentes, costumam serem fracos e residuais, e ocultados pelo ácido protocetrárico.

Parmotrema gardneri (Dodge) Sérusiaux pode ser diferenciada pelo talo coriáceo e que não apresenta pigmentação alaranjada $\mathrm{K}+$ medular (Benatti 2005). Parmotrema dilatatum (Vainio) Hale e P. milanezii Marcelli, Benatti \& Elix (Benatti 2005, Marcelli et al. 2008) podem ser diferenciadas por apresentarem também ácido equinocárpico ( $\mathrm{K}+$ amarelado), outra substância detectável em testes de spot e ainda mais evidentemente em cromatografia. P. praesorediosum (Nylander) Hale diferencia-se pela química medular (sem reações de coloração) e pela ausência de pigmentos.

Parmotrema sulphuratum (Nees \& Flotow) Hale, Phytologia 28(4): 339. 1974. 三 Parmelia sulphurata Nees \& Flotow. Linnaea 9: 501. 1835. Tipo: CUBA. Wright 72 (neótipo UPS, isótipos BM, FH!, K, M, US).

Figuras 6a, b

Talo lobado a sublobado, verde acinzentado amarelado a verde pardo amarelado quando em herbário, até $25,0 \mathrm{~cm}$ diâm., membranáceo a submembranáceo ou raramenete subcoriáceo, corticícola; lobos de ramificação irregular, 1,5-6,5 $(-12,0) \mathrm{mm}$ larg., contíguos a pouco sobrepostos lateralmente, pouco adnatos a mais elevados quando muito isidiados, pouco adpressos, ápices subarredondados, planos a subplanos, as margens lisas a parcialmente crenadas pelo surgimento de isídios, retas a subonduladas, planas a subascendentes e involutas, às vezes pregueadas subcanaliculadas nas axilas, inteiras a incisas, parcialmente sublacinuladas, superfície contínua a irregularmente quebrada nas partes velhas, lisa a rugosa; lacínulas marginais adventícias irregularmente distribuídas, surgindo em meio a isídios e à alguns poucos lóbulos irregulares, simples, truncadas, planas, 0,3-0,6 $\times 0,2-0,3 \mathrm{~mm}$, lado de baixo concolorido à margem inferior; máculas ausentes a fracas, puntiformes, mais visíveis nas partes distais de lobos jovens como um salpicado de pontos amarelos, devido à cor da medula; cílios negros, simples, 0,20-2,50 × ca. 0,05 mm, escassos a freqüentes, marginais mais comuns próximos às axilas dos lobos sendo ausentes ou escassos nos ápices de lobos jovens. Sorais e pústulas ausentes. Isídios cilíndricos lisos ou raramente granulares, às vezes achatados nas bases e parecidos com lacínulas em início de desenvolvimento, 0,05-0,55(-2,55) × 0,05$0,10(-0,25) \mathrm{mm}$, simples a raramente ramificados ou coralóides, eretos, tortuosos, firmes, concoloridos a escurecidos, eciliados ou muito raramente ciliados, parcialmente decorticados a partir dos ápices, surgindo nas margens e em ápices de dobras. Medula amarela forte, brilhante, sem pigmentações alaranjadas do tipo $\mathrm{K}+$. Lado de baixo negro, lustroso, liso a venado ou rugoso, em parte papilado, com trechos rizinados e outros não; margem marrom clara, às vezes creme ou amarelada em parte dos lobos isidiados, lustrosa, 1,06,0 mm larg., atenuada quando marrom a nítida quando creme ou amarelada, lisa a venada ou subrugosa, às vezes papilada na área de transição para o centro, nua; rizinas concoloridas, simples ou às vezes furcadas, $0,10-1,00 \times$ ca. $0,05(-0,10) \mathrm{mm}$, frequientes ou às vezes mais escassas em alguns trechos, agrupadas. Apotécios e picnídios não encontrados.

Testes de coloração e substâncias de importância taxonômica: córtex superior $\mathrm{K}+$ amarelo, $\mathrm{UV}-$ (atranorina); medula $\mathrm{K}-, \mathrm{C}-, \mathrm{KC}-, \mathrm{P}-, \mathrm{UV}-$ (ácido vulpínico e um ácido graxo desconhecido encontrado em CCD).

Distribuição: Oceania, Ásia, África, América do Norte, América Central, Caribe e América do Sul. 
Argentina, Guiana Francesa, Suriname, Venezuela e Brasil: PR e SP (Hale 1965, Krog \& Swinscow 1981, Swinscow \& Krog 1988, Marcelli 1990, Elix 1994, Pooprang et al. 1999, Calvelo \& Liberatore 2000, Benatti 2005, Donha 2005).

Material estudado: BRASIL. São Paulo: Ilha Comprida, parte sul da ilha, mata de restinga próxima à balsa para Cananéia, 2-IV-2004, A.A. Spielmann et al. 809 (SP). Itanhaém, Balneário Santa Cruz, próximo a divisa de municípios entre Itanhaém e Peruíbe, mata de restinga baixa ca. $500 \mathrm{~m}$ da praia, terrenos baldios em área sendo loteada, 14-I-2004, M.N. Benatti et al. 1708 (SP); idem, 14-I-2004, M.N. Benatti et al. 1713 (SP); idem, 14-I-2004, M.N. Benatti et al. 1718 (SP); idem, quase na divisa com Peruíbe, ca. $300 \mathrm{~m}$ do oceano, mata de restinga baixa, 10-II-2004, M.P. Marcelli et al. 36216 (SP); idem, 10-II-2004, M.P. Marcelli et al. 36222 (SP). Peruíbe, Balneário Santa Cruz, próximo à divisa de municípios entre Itanhaém e Peruíbe, mata de restinga baixa ca. $500 \mathrm{~m}$ da praia, 16-XII-2003, M.N. Benatti et al. 1680 (SP). Ubatuba, Ilha Anchieta, Praia das Palmas, mata de restinga, corticícola em pequeno agrupamento de arvoretas, 22-XI-2003, A.A. Spielmann et al. 558 (SP).

Parmotrema sulphuratum pode ser facilmente reconhecida em campo, por causa da forte cor amarela brilhante da medula, devido à presença do ácido vulpínico. Além da coloração de enxofre da medula, $P$. sulphuratum é caracterizada pelas margens ciliadas e geralmente muito isidiadas.

Esta espécie tem isídios finos e cilíndricos, variando de simples a coralóides. Com menos freqüência, podem formar estruturas arbusculares, praticamente idênticas às observadas em Parmelia allardii Hale. Estas estruturas perdem o córtex a partir dos ápices, como se estivesse decompondo em sorédios, mas não formam sorais verdadeiros como os vistos em Parmotrema fasciculatum (Vainio) Hale (Benatti 2005).

É comum observar em $P$. sulphuratum isídios marginais achatados jovens que se parecem às vezes com pequenas lacínulas. Porém, estes desenvolvem formato cilíndrico, ramificando-se variavelmente. Os isídios que não perdem córtex (a maioria) tendem a ser mais escurecidos que o córtex superior. Conforme visto, podem raramente ser ciliados (apesar de que somente alguns talos observados apresentaram isídios ciliados, e ainda assim raros e esparsos).

Donha (2005) mencionou isídios "ocasionalmente sorediando e tornando-se granulares". Como explicado, nenhum espécime encontrado forma de fato sorédios, mesmo que a partir da perda de córtex dos isídios. A menção da autora sobre formação de sorédios a partir de isídios para esta espécie foi a única encontrada (Hale 1965, 1974b, Krog \& Swinscow 1981, Elix 1994, Pooprang et al. 1999, Donha 2005).

Donha (2005) mencionou um córtex quebradiço, freqüentemente deixando à mostra a medula amarelada pela descamação do córtex. Pelo que observou-se nos espécimes deste trabalho, as rachaduras no córtex superior expõem a medula tanto quanto em qualquer outra espécie de Parmotrema de medula rachada, porém chamando mais a atenção pela coloração forte, que "risca" trechos da superfície. Isto está mais de acordo com o mencionado por Sipman (2004), ao dizer que as rachaduras revelam a coloração da medula. Notam-se também vários pontos amarelos, alguns sendo máculas em partes distais de alguns dos lobos jovens salientadas pela forte coloração da medula, e outros que surgem pelo desprendimento dos isídios.

A coloração da medula influi também nas margens inferiores. É comum em espécimes de Parmotrema uma margem inferior branca ou creme quando nos lobos haja apotécios ou propágulos vegetativos, mas em $P$. sulphuratum a margem diferenciada torna-se por transparência fortemente amarelada como a medula, ainda que próxima na aparência da cor do marfim. Quanto ao córtex superior, notou-se que espécimes pequenos e jovens, de talo mais fino, costumam apresentar uma forte tonalidade amarelada devido à coloração da medula.

Com exceção do espécime A.A. Spielmann 558, todos os demais encontrados são membranáceos. Este espécime tem lobos ocasionalmente maiores que a média (até 12,0 mm larg.) e é mais coriáceo, porém nenhuma outra diferença morfológica foi encontrada, e a CCD revelou uma composição química idêntica à dos demais.

Nenhum espécime encontrado continha apotécios ou picnídios. De acordo com Krog \& Swinscow (1981), Elix (1994) e Donha (2005), os conídios são sublageniformes, medindo entre 5,0-6,0(-8,0) × 1,0 $\mu \mathrm{m}$. Não foram encontradas menções para ascósporos.

Parmotrema endosulphureum (Hillmann) Hale difere pela medula conter ácidos secalônicos com coloração menos intensa que a de $P$. sulphuratum (o que também é mencionado por Louwhoff \& Elix 1999), sendo que testes de coloração (K, C, P) realçam a cor da medula da primeira enquanto descolorem a da segunda. Parmotrema endosulphureum tem margens eciliadas, e segundo alguns autores (Hale 1974b, 
Donha 2005) possui ácido girofórico na medula (partes com pigmentação fraca às vezes colorem $\mathrm{C}+\mathrm{e} \mathrm{KC}+$ róseo->alaranjado, embora no material examinado neste trabalho a substância não tenha sido detectada em CCD).

Como citado por Hale $(1965,1974 b) P$. endosulphureum é similar à $P$. tinctorum, sendo que já foi considerada como uma variedade desta espécie. Além das diferenças na coloração da medula e da ausência de cílios, conforme comparados os espécimes de $P$. endosulphureum têm lobos em média mais largos (4,0-14,0 mm) e isídios em geral mais simples (dificilmente sendo coralóides).

Parmotrema aurantiacoparvum Sipman tem a medula completamente impregnada com pigmento alaranjado K+ vermelho escuro, ao invés de substâncias amareladas como os ácidos secalônicos ou vulpínico. Além das diferenças químicas, $P$. aurantiacoparvum tem isídios geralmente muito ciliados, com cílios longos e normalmente maiores que os próprios isídios (ver comentários em $P$. aurantiacoparvum).

\section{Agradecimentos}

Os autores agradecem à assessoria pelas contribuições e revisão do trabalho e ao Conselho Nacional de Desenvolvimento Científico e Tecnológico (CNPq) pelas bolsas de mestrado e de pesquisa concedidas, respectivamente, ao primeiro e segundo autores.

\section{Literatura citada}

Asahina, Y. \& Shibata, S. 1954. Chemistry of Lichen Substances. Japan Society for the Promotion of Science, Tóquio.

Benatti, M.N. 2005. Os gêneros Canomaculina, Parmotrema e Rimelia (Parmeliaceae, Ascomycetes) no litoral centro-sul do estado de São Paulo. Dissertação de Mestrado, Instituto de Botânica, São Paulo.

Benatti, M.N. \& Marcelli, M.P. 2008. Espécies de Parmotrema (Parmeliaceae, Ascomycetes) com máculas reticulares do litoral centro-sul do Estado de São Paulo, Brasil. Hoehnea 35: 75-90.

Benatti, M.N. \& Marcelli, M.P. 2009. Espécies de Parmotrema (Parmeliaceae, Ascomycota) do litoral centro-sul do Estado de São Paulo I. Grupos químicos girofórico e lecanórico Acta Botanica Brasilica 23: 1013-1026.

Brodo, I.M., Sharnoff, S.D. \& Sharnoff, S. 2001. Lichens of North America. Yale University Press. New Haven e London.
Bungartz, F. 2001. Analysis of lichen substances. http:// ces.asu.edu/ASULichens/plb 400/laboratory/chemistry/ tlc.html (acesso em 01/10/2004).

Calvelo, S. \& Liberatore, S. 2000. Checklist, phytogeography and interactive database of Argentinean lichens. In: The Fourth IAL Symposium, Progress and Problems in Lichenology at the turn of the Millenium. Universidad de Barcelona, Barcelona.

Canêz,L.S. 2005. A Família Parmeliaceae na localidade de Fazenda da Estrela, Município de Vacaria, Rio Grande do Sul, Brasil. Dissertação de Mestrado, Instituto de Botânica, São Paulo.

DePriest, P.T \& Hale, B.W. 1998. A validated species and a new combination in Parmotrema (Ascomycotina: Parmeliaceae). Mycotaxon 67: 207-209.

Donha, C.G. 2005. Os gêneros Canomaculina, Parmotrema e Rimelia (Ascomycota Liquenizados) na Área de Proteção Ambiental de Guaraqueçaba, Paraná, Brasil. Dissertação de Mestrado, Universidade Federal do Paraná, Curitiba.

Donha, C.G. \& Eliasaro, S. 2006. Two new species of Parmotrema (Parmeliaceae, lichenized Ascomycota) from Brazil. Mycotaxon 95: 241-245.

Eliasaro, S. 2001. Estudio taxonomico y floristico sobre las Parmeliaceae sensu stricto (Ascomycota liquenizados) del Segundo Planalto del Estado de Paraná, Brasil. Tese de Doutorado, Universidad de Buenos Aires, Buenos Aires.

Eliasaro,S.\& Donha,C.G.2003. The genera Canomaculina and Parmotrema (Parmeliaceae, lichenized Ascomycota) in Curitiba, Paraná State, Brazil. Revista Brasileira de Botânica 26: 239-247.

Elix, J.A. 1994. Parmotrema. In Flora of Australia, Lichens. Introduction, Lecanorales 2. v. 55. Australia Government Publishing Service, Canberra, pp. 140-162.

Fink, B. 1905. How to collect and study lichens. The Bryologist 8: 22-27.

Feuerer, T.E. (ed.) 2005. Checklists of lichens and lichenicolous fungi. Versão I Junho de 2006. In http:// www.checklists.de. (acesso em 05/10/2006).

Fleig, M. 1997. Os gêneros Parmotrema, Rimelia e Rimeliella (Lichenes-Ascomycota, Parmeliaceae) no Rio Grande do Sul, Brasil. Tese de Doutorado, Universidade de São Paulo, São Paulo.

Galloway, D.J. 1985. Flora of New Zealand - lichens. Government Printer, Wellington.

Hale, M.E. 1965. A monograph of the Parmelia subgenus Amphigymnia. Contributions from the United States National Herbarium 36: 193-358.

Hale, M.E. 1974a. New combinations in the lichen genus Parmotrema Massalongo. Phytologia 28: 334-339.

Hale, M.E. 1974b. Notes on species of Parmotrema (Lichenes: Parmeliaceae) containing yellow pigments. Mycotaxon 1: 105-116. 
Hale, M.E. 1979. How to know the lichens. The PicturedKey Nature Series. Wm. C. Brown Company Publishers, Dubuque.

Hale, M.E. 1986. New species in the lichen Family Parmeliaceae (Ascomycotina). Mycotaxon 25: 85-93.

Hale, M.E. 1990. New species of Parmotrema (Ascomycotina: Parmeliaceae) from Tropical America. Bibliotheca Lichenologica 38: 109-119.

Huneck, S. \& Yoshimura, I. 1996. Identification of lichen substances. Springer, Berlin.

Jungbluth, P. 2006. A família Parmeliaceae (fungos liquenizados) em fragmentos de cerrados do Estado de São Paulo. Dissertação de Mestrado, Instituto de Botânica, São Paulo.

Krog, H. \& Swinscow, T.D.V. 1981. Parmelia subgenus Amphigymnia (lichens) in East Africa. Bulletin of British Museum of Natural History, Botany 9: 143-231.

Kurokawa, S.1974. Four new species of Parmelia from Brazil. Bulletin of the Natural Science Museum of Tokyo 17: 297-300.

Kurokawa, S. \& Moon, K.H. 1998. Three new species and a new combination in Parmotrema (Parmeliaceae). Bulletin of the Botanical Garden of Toyama 3: 17-23.

Louwhoff, S.H.J.J. \& Elix, J.A. 1999. Parmotrema and allied lichen genera in Papua New Guinea. Bibliotheca Lichenologica 73: 1-152.

Lynge, B. 1914. Die Flechten der ersten Regnellschen Expedition. Die Gattungen Pseudoparmelia gen. nov. und Parmelia Ach. Arkiv för Botanik 13: 1-172.

Marcelli, M.P. 1990 (1991). Aspects of the foliose lichen flora of the southern-central coast of São Paulo State, Brazil. In: D.J. Galloway (ed). Tropical lichens: their systematics, conservation, and ecology, Systematics Association Special Volume 43. Clarendon Press, Oxford, pp. 151-170.

Marcelli, M.P. 2005. Checklist of Brazilian lichens. Publicação na Internet, pela Universität Hamburg Institut für Allgemeine Botanik, dentro do programa South American Lichens. Em http://www.rra.unihamburg.de/biologie/ialb/herbar/brazi_f2.htm. (acesso em 01/03/2005).

Marcelli, M.P., Benatti, M.N. \& Elix, J.A. 2008. New species of Parmotrema containing protocetraric or stictic acids from the coast of São Paulo State, southeastern Brazil. Mycotaxon 105: 235-248.
Nash III, T.H. \& Elix, J.A. 2002. Parmotrema. In: T.H. Nash III, B.D. Ryan, C. Gries, \& F. Bungartz (eds.). Lichen Flora of the greater Sonoran Desert Region. v. 1. Lichens Unlimited, Arizona State University, Tempe, pp. 318-329.

Orange,A., James,P.W.\& White,F.J.2001.Microchemical methods for the identification of lichens. The British Lichen Society, London.

Pooprang, T., Boonpragob, K. \& Elix, J.A. 1999. New species and new records in the lichen family Parmeliaceae (Ascomycotina) from Thailand. Mycotaxon 71: 111-127.

Ribeiro, C.H. 1998. A família Parmeliaceae (Ascomycota liquenizados) em regiões montanhosas dos estados de Minas Gerais, Rio de Janeiro e São Paulo. Dissertação de Mestrado, Universidade de São Paulo, São Paulo.

Sipman, H.J.M. 2004. Mason Hale's key to Parmotrema, revised edition: key to wide-lobed parmelioid species occurring in Tropical America (genera Canomaculina, Parmotrema, Rimelia, Rimeliella). Em http://www. bgbm.org/sipman/keys/neoparmo.htm. (acesso em 01/07/ 2005).

Sipman, H.J.M. \& Aubel, R.J.M.T. 1992 New Parmeliaceae (Lichenes) from the Guyanas and surroundings. Mycotaxon 44: 1-12.

Spielmann, A.A. 2005. A família Parmeliaceae (fungos liquenizados) nos barrancos e peraus da encosta da Serra Geral, no Vale do Rio Pardo, Rio Grande do Sul, Brasil. Dissertação de Mestrado, Instituto de Botânica, São Paulo.

Swisncow, T.D.V. \& Krog, H. 1988. Macrolichens of East Africa. British Museum of Natural History. London.

Vainio, E.A. 1890. Étude sur la classification naturelle et la morphologie des Lichens du Brésil, pars prima. Acta Societatis pro Fauna et Flora Fennica 7: 1-247.

Vainio, E.A. 1909. Lichenes Insularum Philippinarum, I. Philippine Journal of Science C, Botany, IV, 5: 651-662.

Walker, J.W. \& James, P.W. 1980. A revised guide to microchemical techniques for the identification of lichen products. Bulletin of the British Lichen Society 46 (supl.): 13-29.

White, F.J. \& James, P.W. 1985. A new guide to microchemical techniques for the identification of lichen substances. British Lichen Society Bulletin 57 (supplement): 1-41.

Zahlbruckner, A. 1930. Catalogus Lichenum Universalis. v. 6. Borntraeger, Leipzig. 